\title{
Correction to: Transcriptional and metabolite analysis reveal a shift in direct and indirect defences in response to spider-mite infestation in cucumber (Cucumis sativus)
}

\author{
Jun $\mathrm{He}^{1} \cdot$ Harro J. Bouwmeester $^{2}$ D $\cdot$ Marcel Dicke $^{3}$ (D) $\cdot$ Iris F. Kappers $^{1}$ (D)
}

Published online: 29 April 2020

(c) The Author(s) 2020

\section{Correction to: Plant Molecular Biology https://doi.org/10.1007/s11103-020-01005-y}

In the above mentioned publication, part of Fig. 1b was distorted (48 $\mathrm{h}$ after TSSM Infestation). The original article has been corrected and the proper version of Fig. 1 is also published here.

Publisher's Note Springer Nature remains neutral with regard to jurisdictional claims in published maps and institutional affiliations.

The original article can be found online at https://doi.org/10.1007/ s11103-020-01005-y.

Iris F. Kappers

iris.kappers@wur.nl

1 Laboratory of Plant Physiology, Wageningen University and Research, Wageningen, The Netherlands

2 Swammerdam Institute for Life Sciences, University of Amsterdam, Amsterdam, The Netherlands

3 Laboratory of Entomology, Wageningen University and Research, Droevendaalsesteeg 1, 6708 PB Wageningen, The Netherlands 
(A)
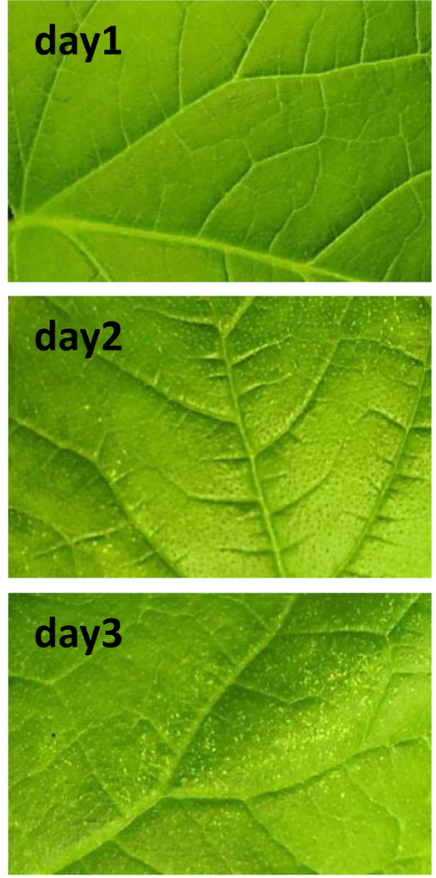

(B)

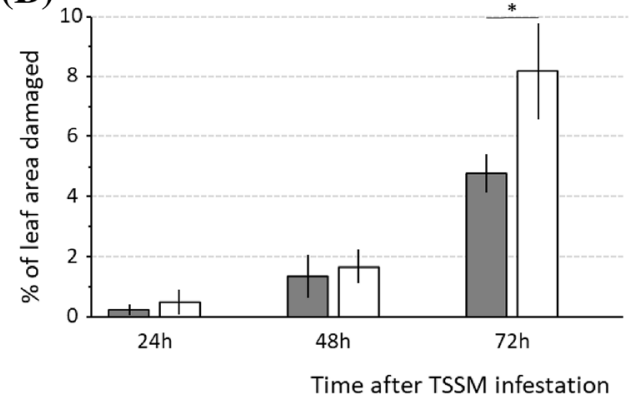

(C)

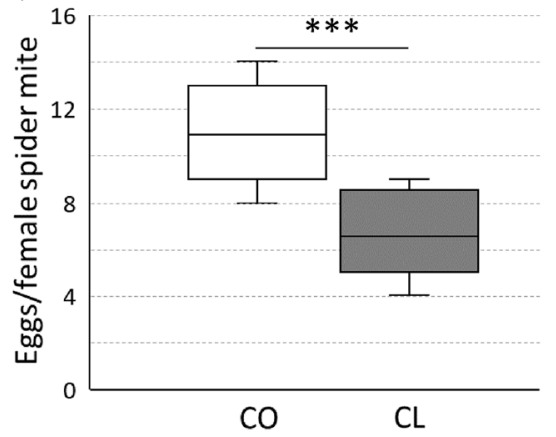

(D)
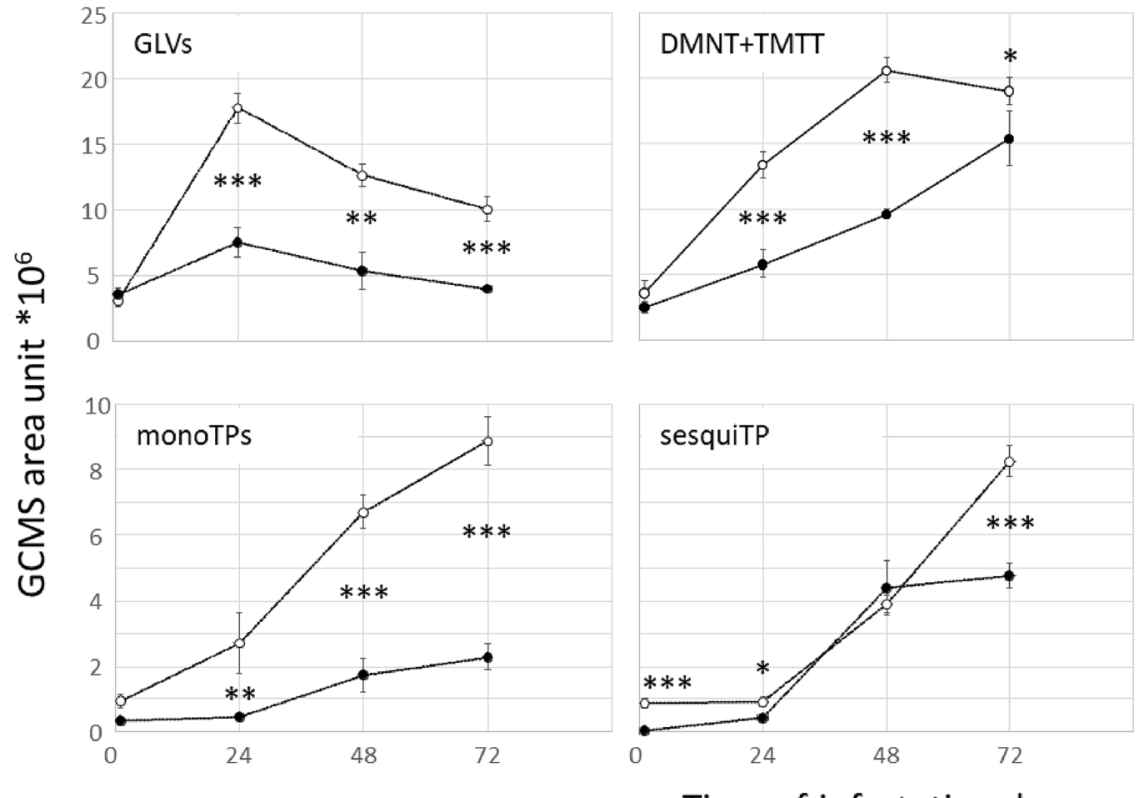

Time of infestation, hrs
$\mathrm{CL}$

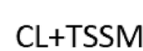

CO

(E)
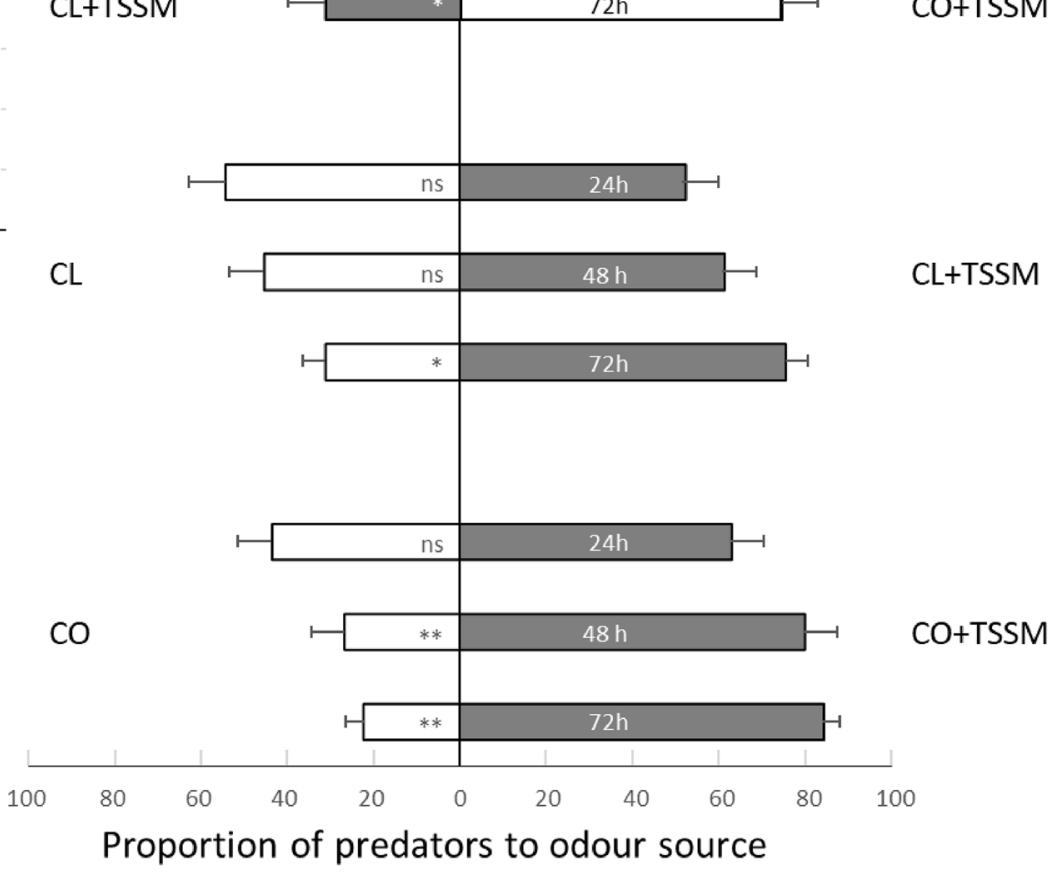
4Fig. 1 Defence responses in cucumber plants infested by two-spotted spider mites. a Visible damage as chlorotic spots in cucumber accession Chinese long (CL) after 1, 2 or 3 days of TSSM infestation; b damaged area as percentage of the total leaf area (means $\pm \mathrm{SD} ; \mathrm{N}=3$ ) in bitter accession Chinese long (CL, grey bars) and non-bitter accession Corona ( $\mathrm{CO}$, white bars); c mean $( \pm \mathrm{SD})$ number of eggs per adult female mite per day produced on leaf discs of Chinese long (CL) or Corona (CO) $(\mathrm{N}=30$ leaf discs with two female mites); $\mathbf{d}$ volatiles emitted by cucumber leaves that were either non-infested or infested with spider mites for 1,2 or 3 days. $C O$ open circles, $C L$ closed circles. GLVs represent the sum (E)-2-hexenal, (Z)-3hexen-1-ol and ( $Z$ )-3-hexenyl acetate, monoTP represent the sum of monoterpenes $\alpha$-pinene, limonene, $(E)$ - $\beta$-ocimene, an unidentified monoterpene and linalool, sesquiTP represent the sum of sesquiterpenes (E)- $\beta$-caryophyllene, $\alpha$-bergamotene, an unidentified sesquiterpene and $(E, E)-\alpha$-farnesene and DMNT+TMTT is the sum of homoterpenes $(E)$-4,8-dimethyl-1,3,7-nonatriene and $(E, E)-4,8,12$ trimethyltrideca-1,3,7,11-tetraene. Data represent mean $\pm \mathrm{SD} ; \mathrm{N}=5$; e relative attraction of predatory mites towards the odour blends of TSSM-infested CL and CO plants compared to non-infested plants and to each other. Data represent mean $\pm \mathrm{SD} ; \mathrm{N}=6$. Differences between genotypes in percentage of damage, oviposition and volatiles on consecutive days were tested for significance using ANOVA after Levine's test for equal variance. Predator preferences were tests using Chi-square test. $n s$ not significant, $* P<0.05, * * P<0.01$, $* * * P<0.001$ 